\title{
Does The Minimally Invasive Quadriceps Sparing Approach Provide Better Short Term Recovery Than The Medial Parapatellar Approach In Primary Total Knee Arthroplasty?
}

\author{
Ilhan Alcelik ${ }^{1}$, Mark Blomfield ${ }^{1}$, Ben Haughton${ }^{1}$, Rachel Taute ${ }^{1 *}$, Cenk Ozturk ${ }^{2}$, David Cash ${ }^{1}$ and Peter Campbell $^{1}$ \\ ${ }^{1}$ Orthopaedics Department, UK
}

${ }^{2}$ Orthopaedics Department, Guven Hospital, Turkey

*Corresponding author: Rachel Taute, Orthopaedics Department, UK

Submission: 監April 11, 2018; Published: 海 May 23, 2018

\begin{abstract}
Purpose: The median parapatellar (MPP) approach is commonly utilised for total knee arthroplasty (TKA). There is an increasing trend towards enhanced recovery and shorter length of hospital stays. It is suggested that the minimally invasive quadriceps sparing (MIQS) TKA can provide both a shorter incision and, by minimizing soft tissue disruption, a quicker recovery. Being technically more demanding the MIQS approach has the potential for increased early complication rates. We performed a systematic review and meta analysis comparing MPP vs MIQS TKA.

Methods: A systematic literature search was performed with only randomised controlled studiesincluded for analysis. Data reported on incision length, knee flexion, straight leg raise,component positioning, knee society scores and post-operative complications were analysed.

Results: Nine studies were included: 342 patients in the MIQS group and 351 in the MPP group. There were statistically significant differences between the groups in terms of operative time, incision length and ability to straight leg raise within the first week. There were more outliers for tibial and femoral component positioning in the MIQS group. There was also a higher complication rate in the MIQS group. There was no statistically significant difference in post-operative functional score.
\end{abstract}

Conclusion: MIQS TKR allows shorter incision and earlier straight leg raise. This analysis raises concerns regarding the rate of complications, particularly component malpositioning, compared with MPP TKA. Over our relatively short term follow up this did not present a statistically significant difference in terms of overall outcome; longer term follow-up is needed to assess this.

Keywords: Minimally invasive; Quadriceps sparing; Total knee arthroplasty; Meta-analysis

\section{Introduction}

OThe medial parapatellar approach (MPP) described by Von Langenbeck in 1879 has become established as the standard technique in the approach to total knee arthroplasty (TKA) (Figure 1) [1]. According to the United Kingdom National Joint Registry, of the 87500 primary total knee arthroplasty (TKA) procedures completed in 2014, 93\% were performed via the MPP approach [2]. It is familiar to most surgeons, provides excellent exposure to all three knee compartments and provides consistent clinical outcomes. However, the relatively extensive exposure leads to soft tissue disruption including division of the quadriceps tendon. The technique usually involves eversion of the patella and is associated with anterior tibio-femoral subluxation. There are concerns that these factors can impede recovery and exacerbate post-operative pain $[3,4]$. Less invasive techniques, as well as providing improved cosmesis, may offer reductions in post operative pain and rehabilitation time, allowing for accelerated discharge and cost savings [4].

A number of less invasive or quadriceps sparing techniques have been described including the midvastus and subvastus approaches (Figure 1). These techniques represent a spectrum of invasiveness and aim (to varying extents) to minimize soft tissue trauma, particularly to the vastus medialis insertion. They are generally associated with a smaller skin incision than the standard MPP approach. However, even with the subvastus approach where vastus medialis is completely avoided the medial intercompartmental fascia and underlying synovium are divided with the potential to cause bleeding and pain. 


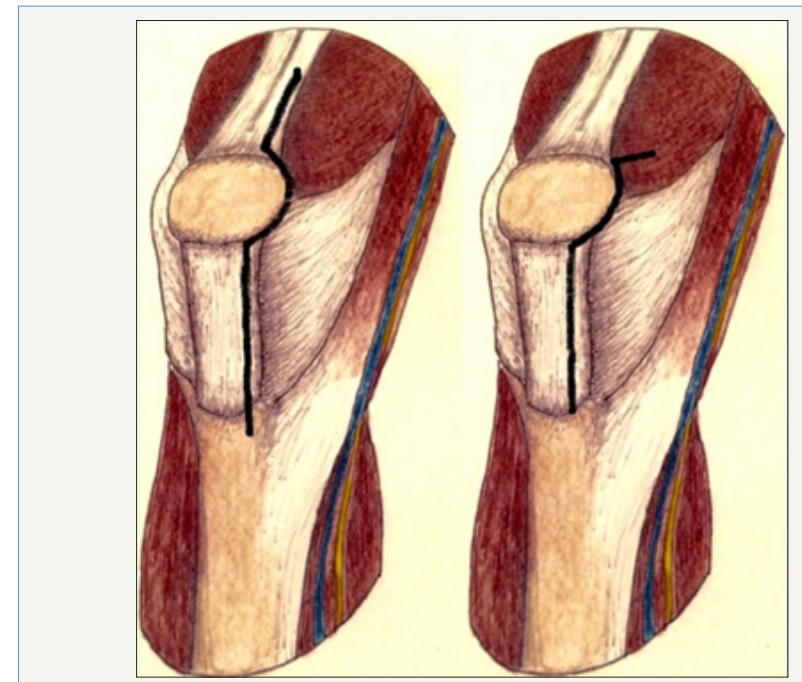

Figure 1: Medial Parapatellar and Midvastus Approaches.

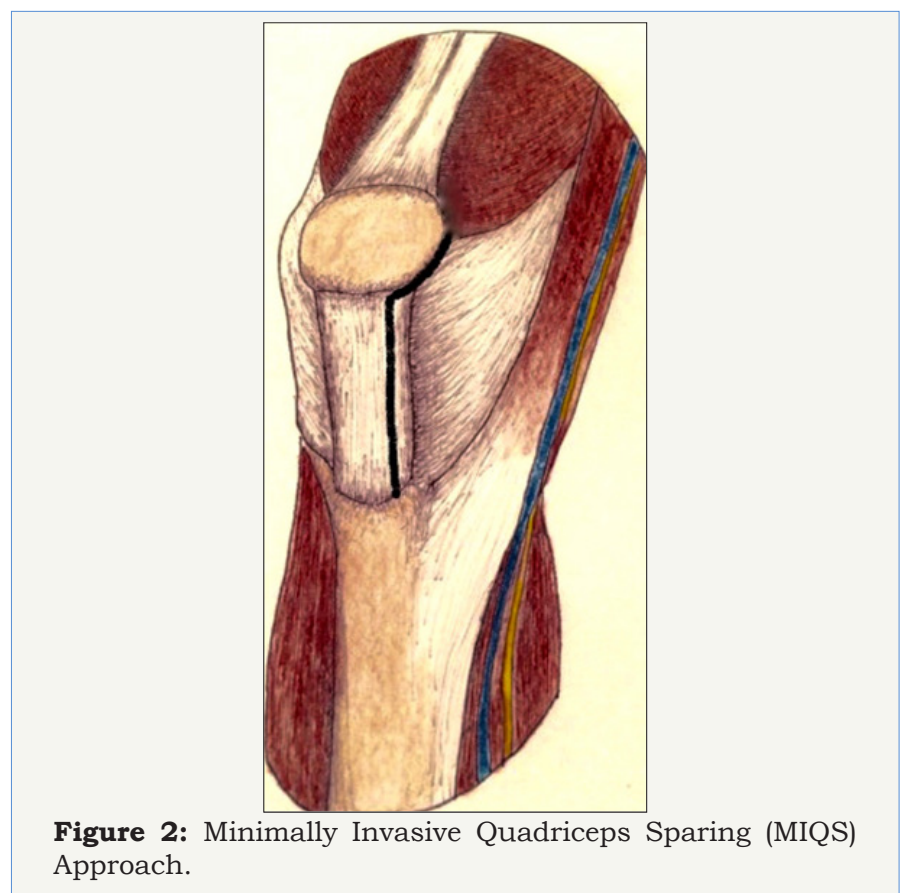

The minimally invasive quadriceps sparing (MIQS) TKA was first introduced by Tria and Coon in 2002 who considered it a less damaging approach to the quadriceps mechanism (Figure 2) [5]. Whereas the subvastus approach involves splitting the fascia and synovium deep to the vastus medialis muscle, the MIQS approach avoids this completely: A medial incision is extended from the superior pole of the patella to the tibial joint line with the arthrotomy in line with the incision with its proximal termination at the inferior edge of the vastus medialis. The quadriceps mechanism is therefore completely avoided: the authors describe making a transverse extension laterally below the vastus if required for exposure.

The MIQS approach offers the least invasive technique described to date and therefore potentially the greatest benefit in terms of accelerated post operative recovery and pain relief. However, concerns remain regarding the potential risk of component malpositioning due to the restricted visual field and resulting early revision rates $[6,7]$.

The hypothesis of this study is that there are significant benefits of utilising the MIQS approach as opposed to using the standard MPP approach on both radiological and clinical grounds in the short term. This hypothesis was tested using a meta-analysis of randomised controlled trials comparing the above two techniques for primary TKA.

\section{Materials and Methods}

A systematic review and meta-analysis was conducted according to guidelines described in the Cochrane handbook for systematic reviews of interventions and PRISMA statement $[8,9]$. We followed the methods of [10].

\section{Study selection criteria}

Types of studies: Only randomised controlled trials were included in this study.

Types of participants: The participants were adult patients who underwent primary TKA using either a MIQS or MPP approach regardless of the type of prosthesis.

Types of interventions: The interventions were MIQS and MPP approaches.

Types of outcome measures: The outcome measures were: Incision length, operation time, range of knee flexion, ability to straight leg raise within first post-operative week, tibial and femoral component coronal axis outliers in post-operative radiographs, Knee Society and Functional scores within the first 3 post-operative months and post-operative complications. Outliers were defined as more than 3 degrees of deviation from neutral alignment. Retrospective studies, animal studies, studies where the above mentioned outcomes are not evaluated, navigation procedures and those where MIQS techniques and MPP approach were not utilised were excluded from this meta-analysis.

\section{Search methods for identification of studies}

Finding existing systematic reviews and meta-analyses: The following databases were searched in September 2015 to identify meta-analyses comparing MIQS approach and MPP approach in TKA: Cochrane Database of Systematic Reviews (CDRS), Database of Abstracts of Reviews of Effects (DARE), and Medline (1950 to September 2015).

Finding published and unpublished primary studies: The following exploded MeSH terms were used for the literature search: "arthroplasty", "replacement", "prosthesis", "invasive", "minimal", "quadriceps" and "knee". A MEDLINE search was then refined to find prospective studies and randomised controlled trials (RCTs) in adult humans. The search was extended to the EMBASE database for studies published in any language from 1966 to September 2015. The bibliographies of retrieved trials were examined for additional articles. The following websites were searched to identify unpublished and ongoing studies: Current Controlled Trials 
(controlled-trials.com); Centre Watch (www.centerwatch.com); Trials Central (www.trialscentral.org); System for Information on Grey Literature in Europe (www.opengrey.eu); The UK National Research Register (www.nihr.ac.uk).

\section{Data collection and analysis}

Selection of the studies: Two authors (IA and CO) applied the search strategy independently and all relevant study abstracts were hand searched by them, after which potentially suitable studies were reviewed in full paper format by each of the authors independently. Disagreement was discussed and resolved with the other authors.

Table 1: Quality assessment scores of included studies.
Assessment of methodological quality of included studies: The review authors used a modification of the generic evaluation tool used by the Cochrane Bone, Joint and Muscle Trauma Group (Table 1) [11]. This includes 12 points where each point is scored 2,1 or 0 (maximum score 24) depending on whether the question was fully, partly or not answered at all for each study. DC and IA performed the quality assessment scoring (QAS) independently, and any disagreements were resolved by discussion and mutual agreement. Total quality assessment score was calculated for each study for descriptive purposes, but it was not used to weight the studies in the meta-analysis or as strict criteria for inclusion/ exclusion.

\begin{tabular}{|c|c|c|c|}
\hline Paper & A-L & Score & Comments \\
\hline Chiang et al. [19] & $2,0,1,0,2,0,1,2,2,2,1,1$ & 14 & $\begin{array}{l}\text { Essentially same study as number } 5 \text { with some authors on both problems. } \\
\text { Better discussion of inclusion criteria, no mention of what happened to those } \\
\text { lost to follow-up. }\end{array}$ \\
\hline Chin et al. [13] & $2,0,1,2,2,0,2,2,2,1,1,0$ & 15 & $\begin{array}{l}\text { Well-designed to answer specific question regarding implant positioning but } \\
\text { no mention of pain scores, functional outcomes. }\end{array}$ \\
\hline Karpman \& Smith [20] & $2,1,0,2,2,0,2,1,2,2,2,1$ & 17 & $\begin{array}{l}\text { Loose exclusion criteria, not clear whether post-operative assessors were } \\
\text { blinded. }\end{array}$ \\
\hline Kim et al. [12] & $2,1,2,2,2,0,2,1,1,2,1,1$ & 17 & $\begin{array}{l}\text { Well-designed study but no muscle power assessment. Some 'quads sparing' } \\
\text { incisions had quads cut termed 'iatrogenic split' and not classed differently. }\end{array}$ \\
\hline Wei-Peng Lin et al. [15] & $2,2,1,1,2,0,1,0,2,2,1,1$ & 15 & $\begin{array}{l}80 \text { knees in } 60 \text { patients, } 2 \text { nd knee done same as first therefore not } \\
\text { randomised. ROM assessor not blinded, no inclusion criteria, not stated who } \\
\text { operated, short follow-up }\end{array}$ \\
\hline Lin et al. [21] & $2,2,0,2,2,0,2,2,2,2,1,2$ & 19 & $\begin{array}{l}\text { Not clear if navigated probes left external scars therefore not completely } \\
\text { blind. No ongoing measurement of knee power. Single surgeon, standard } \\
\text { protocols. }\end{array}$ \\
\hline Matsumoto et al. [22] & $0,0,0,1,2,0,1,0,2,2,0,1$ & 9 & $\begin{array}{l}\text { Poor study. No mention of blinding procedure or operative protocol. No } \\
\text { assessment of clinical outcomes. Use of unverified techniques to measure soft } \\
\text { tissue tension }\end{array}$ \\
\hline Shen et al. [23] & $0,0,0,2,0,0,2,0,2,2,2,2$ & 14 & Good length of follow up on a variety of relevant outcomes. \\
\hline Xu et al. & $1,0,0,2,0,0,2,2,2,2,2,2$ & 15 & $\begin{array}{l}\text { Well-designed study addressing wide variety of outcomes for good length of } \\
\text { follow up. }\end{array}$ \\
\hline
\end{tabular}

\section{Key:}

A. Was the assigned treatment adequately concealed prior to allocation?

$2=$ method did not allow disclosure of assignment

$1=$ small but possible chance of disclosure of assignment or unclear

$0=$ quasi-randomised or open list/tables

B. Were the outcomes of participants who withdrew described and included in the analysis (intention to treat)?

$2=$ withdrawals well described and accounted for in analysis

1 = withdrawals described and analysis not possible

$0=$ no mention, inadequate mention, or obvious differences and no adjustment

C. Were the outcome assessors blinded to treatment status?

$2=$ effective action taken to blind assessors

$1=$ small or moderate chance of unblinding of assessors

$0=$ not mentioned or not possible

D. Were the treatment and control group comparable at entry? (Likely confounders may be age, partial or total rupture, activity level, acute or chronic injury)

2 = good comparability of groups, or confounding adjusted for in analysis 
1 = confounding small; mentioned but not adjusted for

$0=$ large potential for confounding, or not discussed

E. Were the participants blind to assignment status after allocation?

$2=$ effective action taken to blind participants

$1=$ small or moderate chance of unblinding of participants

$0=$ not possible, or not mentioned (unless double-blind), or possible but not done

F. Were the treatment providers blind to assignment status?

$2=$ effective action taken to blind treatment providers

$1=$ small or moderate chance of un blinding of treatment providers

$0=$ not possible, or not mentioned (unless double-blind), or possible but not done

G. Were care programmes, other than the trial options, identical?

$2=$ care programmes clearly identical

$1=$ clear but trivial differences

$0=$ not mentioned or clear and important differences in care programmes

$\mathrm{H}$. Were the inclusion and exclusion criteria clearly defined?

$2=$ clearly defined

$1=$ inadequately defined

$0=$ not defined

I. Were the interventions clearly defined?

2 = clearly defined interventions are applied with a standardised protocol

$1=$ clearly defined interventions are applied but the application protocol is not standardised

$0=$ intervention and/or application protocol are poorly or not defined

J. Were the outcome measures used clearly defined? (by outcome)

2 = clearly defined

1 = inadequately defined

$0=$ not defined

K. Were diagnostic tests used in outcome assessment clinically useful? (by outcome)

2 = optimal

1 = adequate

$0=$ not defined, not adequate

$\mathrm{L}=$ the surveillance active, and of clinically appropriate duration?

2 = active surveillance and appropriate duration

\section{Data extraction and management}

A data extraction form was designed and agreed by the authors. Initially, two authors (IA and MW) extracted the data independently which was later reviewed jointly to produce agreed accurate data.

\section{Statistical analysis}

Meta-analysis, performed by Review Manager (Computer program). (Version 5.3. Copenhagen: The Nordic Cochrane Centre, The Cochrane Collaboration, 2012.), was used to combine the relevant estimates of the effect of interest from the selected studies to provide an overall estimate of the effect. The standard deviations were not present for two studies $[12,13]$ and they were calculated using the range of values given as suggested by [14].
Continuous data for each arm in a particular study were expressed as mean and standard deviation and the treatment effect as mean differences. Dichotomous data for each arm in a particular study were expressed as proportions or risks and the treatment effect as risk ratios. For dichotomous data, the MantelHaenszel method was used to combine the estimates, whereas for continuous data the inverse variance method was utilised. Statistical heterogeneity was assessed using the value of I2 and the result of the chi-squared test. A p value of $<0.1$ and an I2 value greater than $50 \%$ were considered suggestive of statistical heterogeneity, prompting a random effects modelling estimate. Otherwise, a fixed-effect approach was used. On the other hand, a non-significant chi-squared test result only suggested that there is no evidence of heterogeneity. It did not imply that there was 
necessarily homogeneity as there may have been insufficient power to be able to detect heterogeneity.

\section{Results}

Searches for existing meta-analyses comparing MIQS versus MPP in TKA revealed no such meta-analysis in the literature at the time of our initial search in September 2015. However, in October 2015 a study comparing MPP with a range of less invasive approaches (i.e. including mid vastus and sub vastus) was published on line by [15] 1936 primary studies were identified. After duplicates were removed, 1326 studies were excluded based on the inclusion/exclusion criteria, leaving 29 potentially relevant papers for detailed evaluation. This was further reduced to 9 studies for inclusion in the meta-analysis; Figure 3 shows the study selection flow according to PRISMA guidelines. Tomek et al. Yang et al. and Tasker et al. studies are excluded in this meta-analysis [16-18]. In the Tomek study the MIQS approach was actually the subvastus approach, in the Yang et al. study it was midvastus and in the Tasker study the authors mentioned the Bristol quadricepssparing approach initially; however, the approach in fact was either a subvastus or a midvastus approach [19-23]. (Tables $1 \& 2$ ) show the included studies with their quality assessment scores and the characteristics. All the studies were randomised controlled trials. The MIQS approach was used in 342 patients whilst 351 patients underwent the MPP approach.

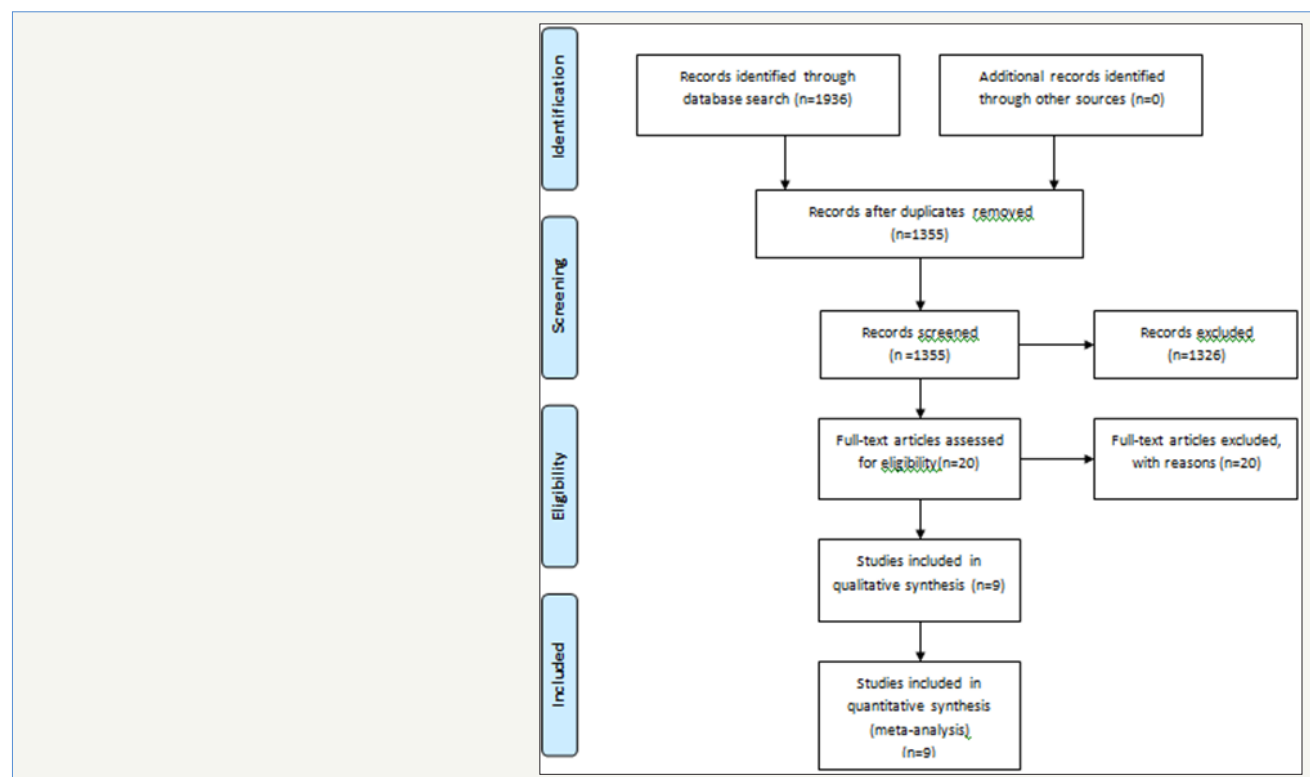

Figure 3: PRISMA chart outlining the study selection process.

Table 2: Characteristics of the included studies.

\begin{tabular}{|c|c|c|c|c|c|c|c|c|c|c|c|c|}
\hline \multicolumn{7}{|c|}{ QS } & \multicolumn{6}{|c|}{ MPP } \\
\hline Authors & $\mathbf{N}$ & Implant & Male & Female & Age & Approach & $\mathbf{N}$ & Implant & Male & Female & Age & Approach \\
\hline $\begin{array}{l}\text { Chiang et } \\
\text { al.[19] }\end{array}$ & 30 & $\begin{array}{l}\text { NexGen, } \\
\text { Zimmer, } \\
\text { Warsaw, IN, } \\
\text { USA }\end{array}$ & 3 & 27 & $69.7 \pm 5.3$ & $\begin{array}{l}\text { quadriceps } \\
\text { sparing }\end{array}$ & 30 & $\begin{array}{c}\text { NexGen, } \\
\text { Zimmer, } \\
\text { Warsaw, IN, } \\
\text { USA }\end{array}$ & 3 & 27 & $69.8 \pm 5.4$ & $\begin{array}{c}\text { standard } \\
\text { medial } \\
\text { parapatellar }\end{array}$ \\
\hline $\begin{array}{l}\text { Chin et } \\
\text { al.[13] }\end{array}$ & 30 & $\begin{array}{c}\text { NexGen, } \\
\text { Zimmer, } \\
\text { Warsaw, IN, } \\
\text { USA }\end{array}$ & 6 & 24 & $\begin{array}{c}69.0(57- \\
80)\end{array}$ & $\begin{array}{l}\text { quadriceps } \\
\text { sparing }\end{array}$ & 30 & $\begin{array}{l}\text { NexGen, } \\
\text { Zimmer, } \\
\text { Warsaw, } \\
\text { IN, USA \& } \\
\text { PFC Sigma } \\
\text { Johnson \& } \\
\text { Johnson } \\
\text { Plaza New } \\
\text { Brunswick, } \\
\text { New Jersey, } \\
\text { USA }\end{array}$ & 3 & 27 & $\begin{array}{c}63.4(47- \\
80)\end{array}$ & $\begin{array}{c}\text { standard } \\
\text { medial } \\
\text { parapatellar }\end{array}$ \\
\hline $\begin{array}{c}\text { Karpman \& } \\
\text { Smith [21] }\end{array}$ & 20 & $\begin{array}{c}\text { NexGen, } \\
\text { Zimmer, } \\
\text { Warsaw, IN, } \\
\text { USA }\end{array}$ & 8 & 12 & $73 \pm 7.4$ & $\begin{array}{l}\text { quadriceps } \\
\text { sparing }\end{array}$ & 19 & $\begin{array}{l}\text { NexGen, } \\
\text { Zimmer, } \\
\text { Warsaw, IN, } \\
\text { USA }\end{array}$ & 9 & 10 & $73 \pm 5.1$ & $\begin{array}{c}\text { standard } \\
\text { medial } \\
\text { parapatellar }\end{array}$ \\
\hline
\end{tabular}




\begin{tabular}{|c|c|c|c|c|c|c|c|c|c|c|c|c|}
\hline $\begin{array}{c}\text { Kim et al. } \\
\text { [12] }\end{array}$ & 120 & $\begin{array}{c}\text { NexGen, } \\
\text { Zimmer, } \\
\text { Warsaw, IN, } \\
\text { USA }\end{array}$ & 27 & 93 & $\begin{array}{c}65.4(43- \\
88)\end{array}$ & $\begin{array}{l}\text { quadriceps } \\
\text { sparing }\end{array}$ & 120 & $\begin{array}{l}\text { NexGen, } \\
\text { Zimmer, } \\
\text { Warsaw, IN, } \\
\text { USA }\end{array}$ & 27 & 93 & $\begin{array}{c}65.4(43- \\
88)\end{array}$ & $\begin{array}{c}\text { standard } \\
\text { medial } \\
\text { parapatellar }\end{array}$ \\
\hline $\begin{array}{c}\text { Lin et al. } \\
\text { [25] }\end{array}$ & 35 & $\begin{array}{c}\text { NexGen, } \\
\text { Zimmer, } \\
\text { Warsaw, IN, } \\
\text { USA }\end{array}$ & 5 & 30 & $\begin{array}{c}67.7(60- \\
78)\end{array}$ & $\begin{array}{l}\text { quadriceps } \\
\text { sparing }\end{array}$ & 35 & $\begin{array}{l}\text { NexGen, } \\
\text { Zimmer, } \\
\text { Warsaw, IN, } \\
\text { USA }\end{array}$ & 5 & 30 & $\begin{array}{c}68.5(55- \\
77)\end{array}$ & $\begin{array}{l}\text { mini medial } \\
\text { parapatellar }\end{array}$ \\
\hline $\begin{array}{c}\text { Wei Peng } \\
\text { Lin et al. } \\
\text { [15] }\end{array}$ & 30 & $\begin{array}{c}\text { NexGen, } \\
\text { Zimmer, } \\
\text { Warsaw, IN, } \\
\text { USA }\end{array}$ & 3 & 27 & $\begin{array}{c}70.2(56- \\
82)\end{array}$ & $\begin{array}{l}\text { quadriceps } \\
\text { sparing }\end{array}$ & 30 & $\begin{array}{c}\text { NexGen, } \\
\text { Zimmer, } \\
\text { Warsaw, IN, } \\
\text { USA }\end{array}$ & 3 & 27 & $\begin{array}{c}69.6(57- \\
78)\end{array}$ & $\begin{array}{l}\text { mini medial } \\
\text { parapatellar }\end{array}$ \\
\hline $\begin{array}{l}\text { Matsumoto } \\
\text { et al. [23] }\end{array}$ & 25 & $\begin{array}{c}\text { NexGen, } \\
\text { Zimmer, } \\
\text { Warsaw, IN, } \\
\text { USA }\end{array}$ & 0 & 25 & $\begin{array}{c}73.8 \\
(55-85)\end{array}$ & $\begin{array}{l}\text { quadriceps } \\
\text { sparing }\end{array}$ & 25 & $\begin{array}{c}\text { NexGen, } \\
\text { Zimmer, } \\
\text { Warsaw, IN, } \\
\text { USA }\end{array}$ & 0 & 25 & $\begin{array}{c}73.7(55- \\
86)\end{array}$ & $\begin{array}{c}\text { standard } \\
\text { medial } \\
\text { parapatellar }\end{array}$ \\
\hline $\begin{array}{c}\text { Shen et al. } \\
{[24]}\end{array}$ & 26 & $\mathrm{~N} / \mathrm{S}$ & $\mathrm{N} / \mathrm{S}$ & $\mathrm{N} / \mathrm{S}$ & $\mathrm{N} / \mathrm{S}$ & $\begin{array}{l}\text { quadriceps } \\
\text { sparing }\end{array}$ & 33 & $\mathrm{~N} / \mathrm{S}$ & $\mathrm{N} / \mathrm{S}$ & $\mathrm{N} / \mathrm{S}$ & $\mathrm{N} / \mathrm{S}$ & $\begin{array}{c}\text { standard } \\
\text { medial } \\
\text { parapatellar }\end{array}$ \\
\hline Xu et al. & 26 & $\begin{array}{c}\text { PFC Sigma } \\
\text { Johnson \& } \\
\text { Johnson } \\
\text { PlazaNew } \\
\text { Brunswick, } \\
\text { New Jersey, } \\
\text { USA }\end{array}$ & 7 & 19 & $63 \pm 8.7$ & $\begin{array}{l}\text { quadriceps } \\
\text { sparing }\end{array}$ & 29 & $\begin{array}{c}\text { PFC Sigma } \\
\text { Johnson \& } \\
\text { Johnson } \\
\text { PlazaNew } \\
\text { Brunswick, } \\
\text { New Jersey, } \\
\text { USA }\end{array}$ & 11 & 18 & $64.2 \pm 9.3$ & $\begin{array}{c}\text { standard } \\
\text { medial } \\
\text { parapatellar }\end{array}$ \\
\hline
\end{tabular}

\section{Operative time}

Six studies reported this outcome [12,13,19,20,24,25]. The Chi-square test for heterogeneity on the included six studies was $65.55(\mathrm{df}=5, \mathrm{P}<0.00001)$ and a random effects analysis model was performed. There were 283 knees in the MIQS group and 281 knees in the MPP group. Operative time was significantly longer in the MIQS group (Table 3), with a mean difference of 19.58 minutes (95\% CI 11.42 to $27.74, \mathrm{P}<0.00001)$.

Table 3: Operation time.

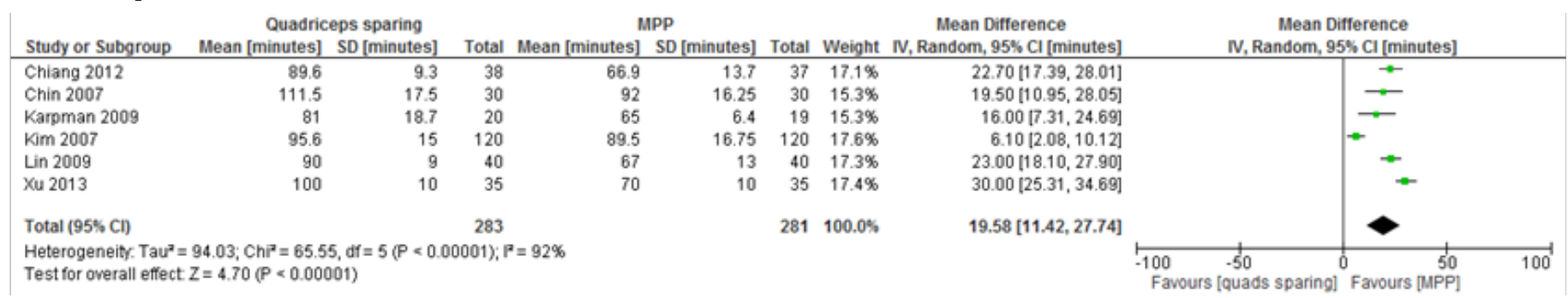

\section{Incision length}

Seven studies reported on the incision length [12,19,20-23,25]. Again, a random effect analysis model used as Chi-square test for heterogeneity was 2397.81, $(\mathrm{df}=6, \mathrm{P}<0.00001)$. There were 304 knees in the MIQS group and 309 knees in the MPP group. Incision length was significantly shorter in the MIQS group with a mean difference of 2.81 centimetres. ( $95 \% \mathrm{CI},-5.52$ to $-0.09, \mathrm{P}=0.04$ ) (Table 4).

Table 4: Incision length.

[quads sparing] MPP

Mean Difference 95 Cl [centimeter] Chiang 2012 Karpman 2009 Kim 2007 Lin 2009 Matsumoto 2011 Shen 2007 Xut 2013

$\begin{array}{rrr}12.2 & 0.9 & 38 \\ 8.4 & 1.2 & 20 \\ 12.4 & 1 & 120 \\ 12.2 & 0.9 & 40 \\ 9.2 & 0.2 & 25 \\ 9.5 & 1.5 & 26 \\ 15 & 2 & 35\end{array}$

Total $195 \% \mathrm{Cl})$ 304 Heterogeneity. Tau $^{2}=13.34 ; \mathrm{Ch}^{2}=2397.81, \mathrm{df}=6(\mathrm{P}<0.00001), \mathrm{P}^{2}=100 \%$ Test for overall effect $Z=2.03(P=0.04)$ $-0.70+-1.09,-0.31]$

$\begin{array}{rrrrr}12.9 & 0.8 & 37 & 14.3 \% & -0.70+1.09,-0.31] \\ 10.7 & 1.2 & 19 & 14.2 \% & -2.30[-3.05,-1.55] \\ 12.5 & 1.25 & 120 & 14.4 \% & -0.10[-0.39,0.19] \\ 12.9 & 0.8 & 40 & 14.3 \% & -0.70[-1.07,-0.33] \\ 15.6 & 0.3 & 25 & 14.4 \% & -6.40[-6.54,-6.26] \\ 14 & 2.3 & 33 & 14.1 \% & -4.50+5.47,-3.53] \\ 20 & 1 & 35 & 14.2 \% & -5.00[-5.74,-4.26]\end{array}$

$309100.0 \%$
$-2.81[-5.52,-0.09]$

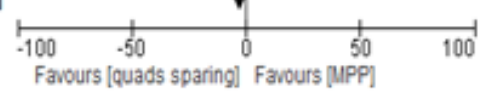




\section{Straight leg raise within the first week post-operatively}

4 studies reported on this outcome $[19,21,23,24]$. There were 127 knees in the MIQS group and 138 knees in the MPP group. The results showed significantly more straight leg raises in the first

Table 5: Straight leg raise.

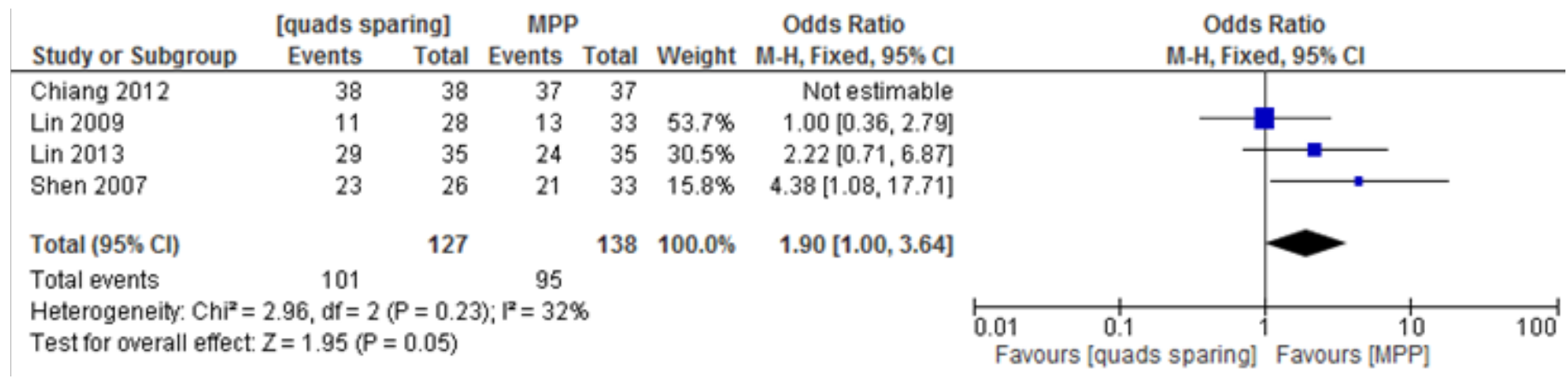

\section{Knee flexion within the first week post-operatively}

Only 3 studies reported this outcome involving 84 knees in the MIQS group and 89 in the MPP group $[19,21,24]$. The random effect

Table 6: Knee flexion. post-operative week in the MIQS group in comparison to the MPP group (101 vs 95). The Chi-square test for heterogeneity was 2.96 $(\mathrm{df}=2, \mathrm{P}=2.3)$ and therefore a fixed effect analysis model was used. The odds ratio between the MIQS group and MPP group was 1.9 (CI 95\%, 1.00 to $3.64, \mathrm{P}=0.05$ ) (Table 5). model was used as the chi-square test for heterogeneity was 14.03 $(\mathrm{df}=2, \mathrm{P}=0.0009)$. The mean difference was 6.12 degrees $(95 \% \mathrm{CI}$, -3.58 to $15.81, \mathrm{P}=0.22$ ). This difference between the MIQS and the MPP groups was not statistically significant (Table 6).

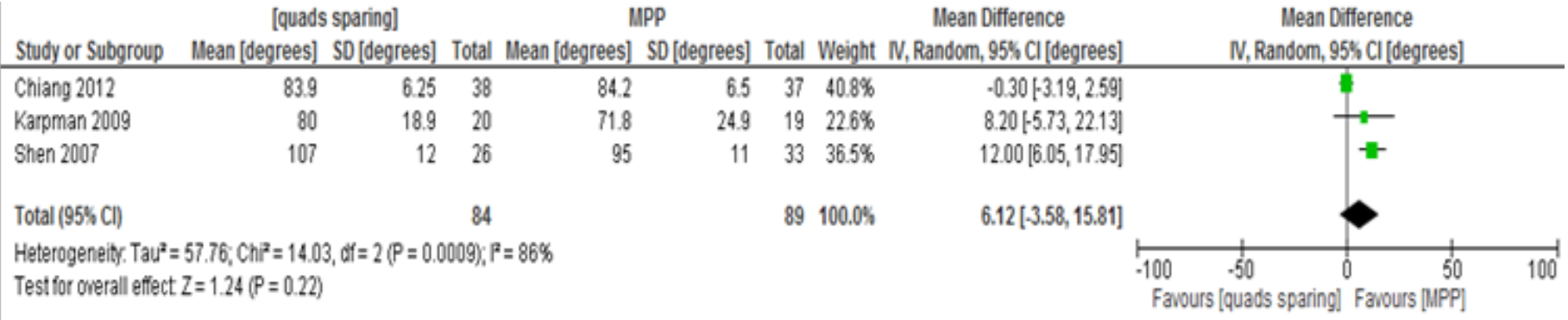

Knee society scores within the first three months postoperatively

3 studies reported on Knee Society scores on 181 knees in the MIQS group versus 188 in the MPP group [12,20,24]. The Chi- square test for heterogeneity was $7.77(\mathrm{df}=2, \mathrm{P}=0.02)$ and random effect modelling was used. There was no statistically significant difference in the scores between the two groups. The mean difference was 1.21 points; $95 \% \mathrm{CI},-0.92$ to $3.35, \mathrm{P}=0.27$ (Table 7).

Table 7: Knee Society scores.

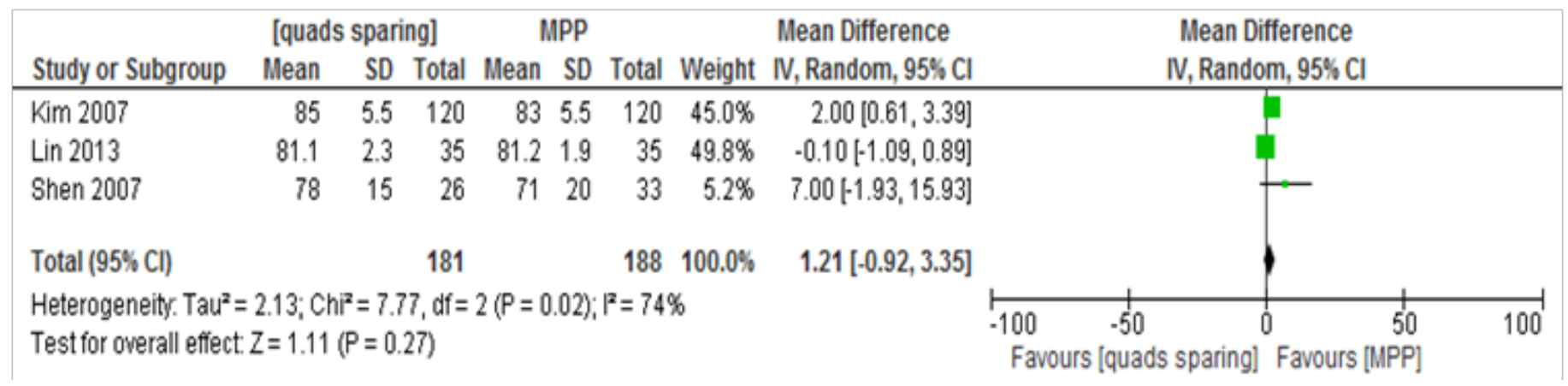

\section{Knee society functional scores within the first three months post-operatively}

Only 2 studies reported on Knee Society functional scores in a total of 155 knees $[12,24]$. The Chi-square test for heterogeneity was $3.02(\mathrm{df}=1, \mathrm{P}=0.08)$ and random effect modelling was used. There was no statistically significant difference in the scores between the two groups. The mean difference was 1.60 points; $95 \% \mathrm{CI},-1.76$ to 4.96, $\mathrm{P}=0.35$ (Table 8).

\section{Coronal plane tibial component outliers}

4 studies were eligible for this outcome including 143MIQS and 142MPP knees $[13,19,21,24]$. There were 16 outliers in the first group and 3 in the second, with an odds ratio of 4.72 (95\% CI, 1.57 to $14.15, \mathrm{p}=0.006$ ) indicating a statistically significant result (Table 9). The test for heterogeneity showed a Chi-square test of $0.66, \mathrm{df}=3, \mathrm{P}=0.88$ and fixed effect modelling was utilised. 
Table 8: Knee Society functional scores.

\begin{tabular}{|c|c|c|c|c|c|c|c|c|c|c|}
\hline \multirow[b]{2}{*}{ Study or Subgroup } & \multicolumn{3}{|c|}{ [quads sparing] } & \multicolumn{3}{|c|}{ MPP } & \multicolumn{2}{|r|}{ Mean Difference } & \multirow{2}{*}{$\begin{array}{c}\text { Mean Difference } \\
\text { IV, Random, } 95 \% \mathrm{Cl}\end{array}$} & \\
\hline & Mean & SD & Total & Mean & SD & Total & Weight & IV, Random, $95 \% \mathrm{Cl}$ & & \\
\hline Kim 2007 & 76 & 6.25 & 120 & 73 & 7.5 & 120 & $60.1 \%$ & $3.00[1.25,4.75]$ & & \\
\hline Lin 2013 & 82.9 & 7.7 & 35 & 83.4 & 7.4 & 35 & $39.9 \%$ & $-0.50[-4.04,3.04]$ & & \\
\hline Total $(95 \% \mathrm{Cl})$ & & & 155 & & & 155 & $100.0 \%$ & $1.60[-1.76,4.96]$ & & \\
\hline $\begin{array}{l}\text { Heterogeneity. } \operatorname{Tau}^{2}= \\
\text { Test for overall effect }\end{array}$ & $\begin{array}{l}4.10 ; \mathrm{Cr} \\
Z=0.93\end{array}$ & $\begin{array}{l}P^{2}=3 . C \\
P=0 .\end{array}$ & $\begin{array}{l}2, \mathrm{df}= \\
35)\end{array}$ & $1(P=0$ & $.08) ;$ & $P^{2}=679$ & & & $\begin{array}{cccc}! & 1 & 1 & 1 \\
& \text { Favours [quads sparing] } & \text { Favours [MPP] }\end{array}$ & 100 \\
\hline
\end{tabular}

Table 9: Coronal plane tibial component outliers.

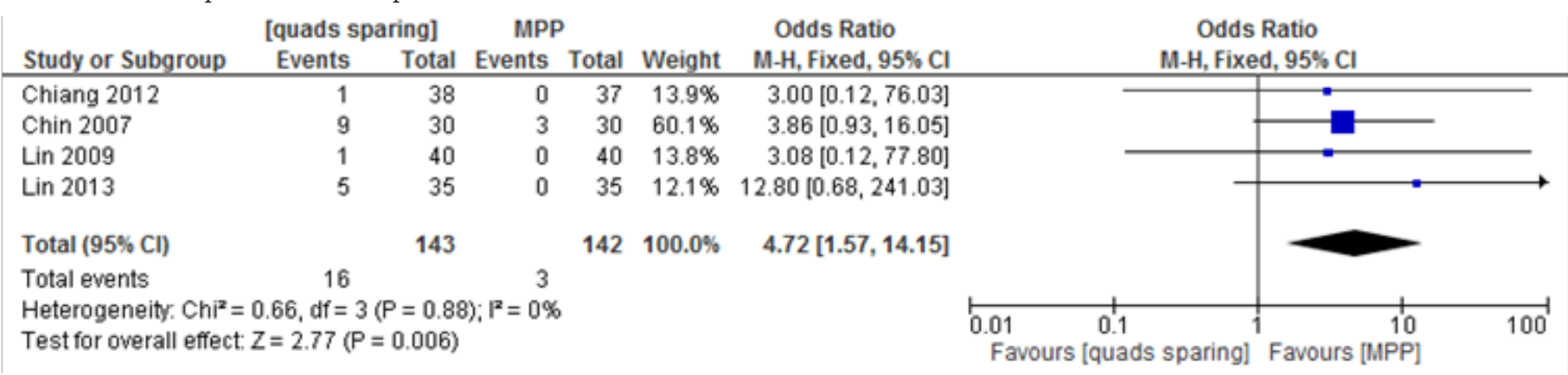

\section{Coronal plane femoral component outliers}

The same 4 studies as above were suitable for assessment of coronal plane femoral component outliers in the same number of knees. There were 21 outliers in the MIQS group and 3 in the MPP

Table 10: Coronal plane femoral component outliers.

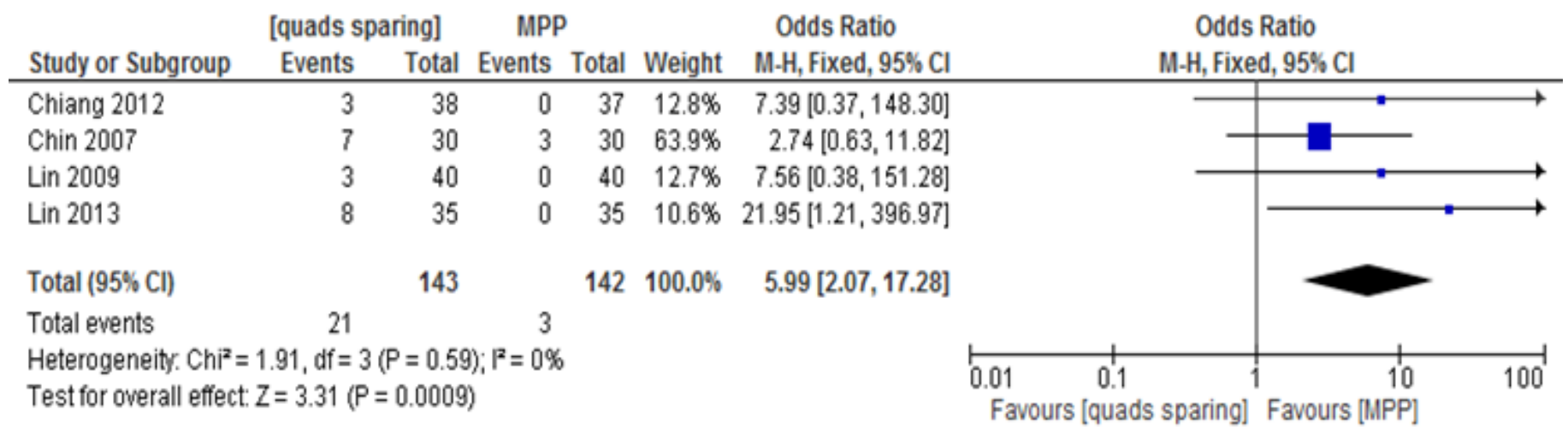

\section{Post-operative complications}

Table 11: Post-operative complications.

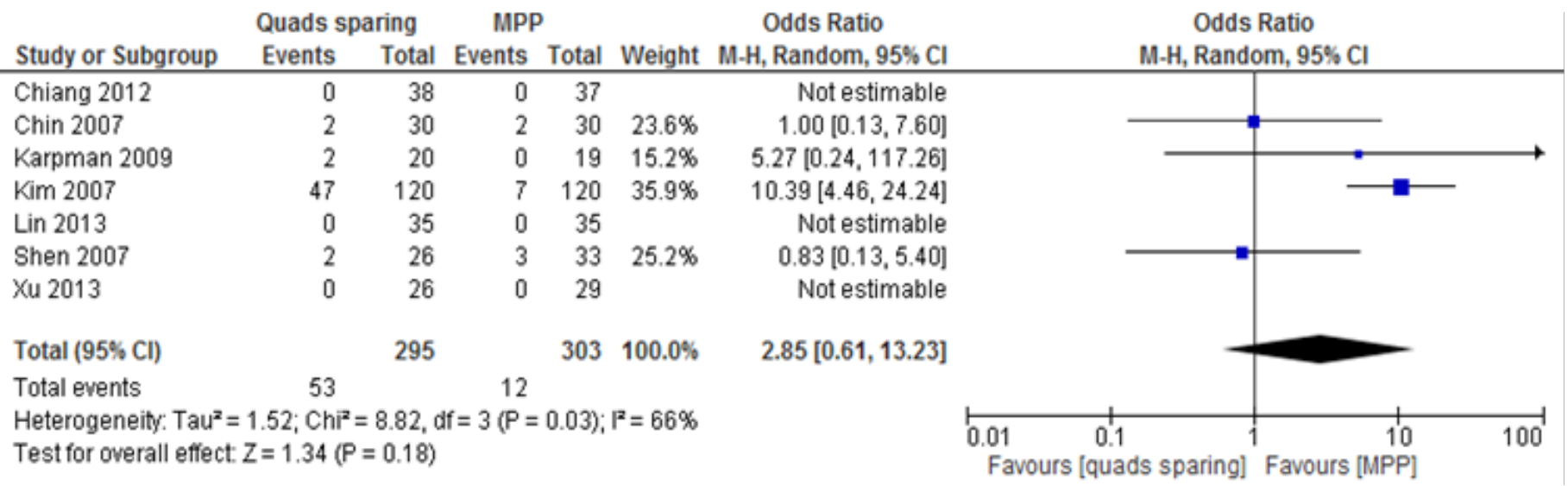


7 studies included this outcome on 295 patients in the MIQS group and 303 patients in the MPP group [12,13,19,20,2325]. There were no complications in either group in 3 of the 7 included studies $[19,24,25]$. The remaining 4 studies reported 53 complications in the MIQS group and 12 in the MPP group. The Chisquare test for heterogeneity was $8.82(\mathrm{df}=3, \mathrm{P}=0.03)$, indicating statistical heterogeneity on all included studies and a random effects analysis model was used. The odds ratio between the MIQS and the MPP group was 2.85 (CI 95\%, 0.61 to $13.23, \mathrm{P}=0.18$ ) and this result was not statistically significant (Table 11). Shen et al. reported one deep vein thrombosis (DVT) in MIQS and 3 in the MPP group as well as one superficial wound necrosis in the MIQS group [23]. In Chin et al.'s study, 1 patient required manipulation under anaesthetic for post-operative knee stiffness in the MIQS group and in the same group there was a superficial wound infection, whereas in the MPP group there were 2 cases of deep vein thrombosis [13]. In the Karpman et al. study there were no complications in the

Table 12: Funnel plot: incision length.

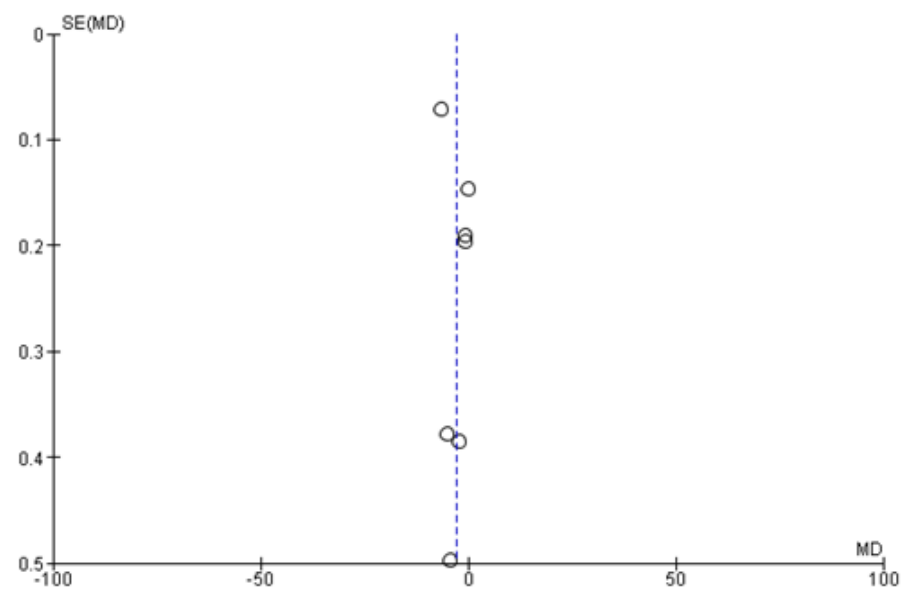

\section{Discussion}

Our findings showed that there was a statistically significant difference in the number of outliers in both coronal plane tibial and femoral components; with the medial parapatellar group performing better. This is consistent with Dalury and Dennis' concerns and report on the potential for component malalignment in minimally invasive surgery [26]. There were no statistically significant differences between the groups on Knee Society Scores and Functional Scores within the first 3 months following surgery. However, it is worth pointing out that there were only 2 studies which looked at the functional scores and 3 studies on Knee Society Scores in the meta-analysis. The number of patients who were able to perform straight leg raises within the first postoperative week was significantly greater in the MIQS group (101 knees on 127 cases vs. 95 knees on 138 cases).The other statistical difference between the groups was the longer operating time in the MIQS group. MIQS surgery took almost 20 minutes longer on average. Regarding the complications; there were more complications in the MIQS group but this did not reach statistical significance; it may however have clinical relevance. It is not clear from this study if
MPP group. However, there were 2 cases of infections in the MIQS group, one being deep which, despite initial surgical treatment, later required a revision procedure [20]. Kim et al. reported the most complications: 31 cases of quadriceps tendon lacerations, 2 popliteal tendon lacerations, 2 deep peroneal nerve palsies (both resolved), 1 case of patellar tendon avulsion, 5 cases of femoral notching, 2 fractures, 1 deep and 1 superficial infection and finally a case of DVT in the MIQS group. In the same paper, there were 2 cases of notching, 1 deep and 1 superficial infection and 3 fractures in the MPP group [12].

\section{Publication bias}

The incision length was one of the most commonly used outcomes by the studies. Therefore, a funnel plot was produced to assess publication bias. This showed a roughly symmetrical distribution indicating minimal evidence of a publication bias (Table 12).

the higher complication rate is due to the operative technique or related to the increased operative time. The knee flexion outcome was also not significantly different between the groups within the first week. Therefore; the MIQS approach is superior to MPP techniques in relation to straight leg raising within the first week. However, it takes significantly longer to perform and there are significantly more radiological outliers in the MIQS approach group in comparison to the MPP group.

Peng et al. recently published a meta analysis on a similar subject and concluded that quadriceps sparing approaches were associated with better outcomes in both Knee Society and visual analogue scores at the expense of operative time [15]. They also included 9 studies in their meta-analysis but chose to omit the randomised controlled trial comparing conventional and minimally invasive techniques for TKA by Chin et al, and yet included the study by Tasker, whose "quadriceps sparing' group contained a mixture of both midvastus and subvastus approach depending on the operating surgeon [18]. We believe that our robust and consistent inclusion criteria of carefully selected studies combined with our meta-analysis methodology gives confidence to our conclusions.

The limitations of our study are significant heterogeneity between findings for some of the outcomes measured. Variations which may have accounted for such heterogeneity include the following; the difference in sample sizes, the variation of patients' demographics such as race, age, gender and BMI, different inclusion and exclusion criteria for each study and the differences in management protocols between centres. Furthermore, there is insufficient data to support the analysis of medium or long term outcomes at present. Therefore, there is a need for well designed randomised controlled studies to investigate the long term success of this technique in the future.

\section{Acknowledgement}

The authors extend their gratitude to the York Hospital York Hospital Librarians for their support in providing the necessary 
papers; to Cai-Shun Zhong from Jiangxi Normal University for help with translation of the Chinese papers in our study and to Michael Lyth for his assistance with the illustrations.

\section{References}

1. Von Langenbeck B (1879) Zur resection des kniegellenks, Verhandl d Deutschen Gesellsch f Chir VII 23.

2. Summary of Annual Statistics. National Joint Registry, UK.

3. Gandhi R, Dhotar H, Razak F, Tso P, Davey JR, et al. (2010) Predicting the longer term outcomes of total knee arthroplasty. The Knee 17(1): 15-18.

4. Sloan FA, George LK, Hu L (2013) Longer term effects of total knee arthroplasty from a national longitudinal study. J aging health 25(6): 982-997.

5. Tria AJ, Coon TM (2003) Minimal incision total knee arthroplasty: early experience. Clin Orthop Relat Res 416: 185-190.

6. Hernandez-Vaquero D (2010) Comments on Bonutti PM et al.: Minimally invasive total knee arthroplasty using the contralateral knee as a control group: a case-control study. Int Orthop 34(7): 1073-1074.

7. Barrack RL, Barnes CL, Burnett RS, Miller D, Clohisy JC, et al. (2009) Minimal incision surgery as a risk factor for early failure of total knee arthroplasty. J Arthroplasty 24(4): 489-498.

8. Higgins JPT, Green S (2006) Cochrane Handbook for Systematic Reviews of Interventions 4.2.2. John Wiley \& Sons, Ltd, The Cochrane Library, UK, p. 4 .

9. Moher D, Liberati A, Tetzlaff J, Altman DG (2009) Preferred reporting items for systematic reviews and meta-analyses: the PRISMA statement. PLoS Med 6(7): e1000097.

10. Alcelik IA, Blomfield MI, Diana G, Gibbon AJ, Carrington N, et al. (2016) A Comparison of Short-Term Outcomes of Minimally Invasive ComputerAssisted vs Minimally Invasive Conventional Instrumentation for Primary Total Knee Arthroplasty. J Arthroplasty 31(2): 410-418.

11. Handoll H, Elstub L, Elliot J (2008) Cochrane bone, joint and muscle trauma group. About the Cochrane collaboration (Cochrane review groups (CRGS)) Issue 4 Art. No: MUSKINJ.

12. Kim YH, Kim JS, Kim DY (2007) Clinical outcome and rate of complications after primary total knee replacement performed with quadricepssparing or standard arthrotomy. J Bone Joint Surg Br 89(4): 467-470.

13. Chin PL, Foo LS, Yang KY, Yeo SJ, Lo NN (2007) Randomized controlled trial comparing the radiologic outcomes of conventional and minimally invasive techniques for total knee arthroplasty. J Arthroplasty 22(6): 800-806.

14. Hozo SP, Djulbegovic B, Hozo I (2005) Estimating the mean and variance from the median, range, and the size of a sample. BMC Med Res Methodol 5(1): 13.
15. Peng X, Zhang X, Cheng T, Cheng M, Wang J (2015) Comparison of the quadriceps-sparing and subvastus approaches versus the standard parapatellar approach in total knee arthroplasty: a meta-analysis of randomized controlled trials. BMC Musculoskel Dis 16(1): 327.

16. Tomek IM, Kantor SR, Cori LA, Scoville JM, Grove MR, Morgan TS, et al. (2014) Early Patient Outcomes After Primary Total Knee Arthroplasty with Quadriceps-Sparing Subvastus and Medial Parapatellar Techniques: A Randomized, Double-Blind Clinical Trial. J Bone Joint Surg Am 96(11): 907-915.

17. Yang JH, Yoon JR, Pandher DS, Oh KJ (2010) Clinical and radiologic outcomes of contemporary 3 techniques of TKA. Orthopedics 33(10 Suppl): 76-81.

18. Tasker A, Hassaballa M, Murray J, Lancaster S, Artz N, et al. (2014) Minimally invasive total knee arthroplasty; a pragmatic randomised controlled trial reporting outcomes up to 2 year follow up. Knee 21(1): 189-193.

19. Chiang H, Lee CC, Lin WP, Jiang CC (2012) Comparison of quadricepssparing minimally invasive and medial parapatellar total knee arthroplasty: a 2-year follow-up study. J Formos Med Assoc 111(12): 698-704.

20. Karpman RR, Smith HL (2009) Comparison of the early results of minimally invasive vs standard approaches to total knee arthroplasty: a prospective, randomized study. J Arthroplasty 24(5): 681-688.

21. Lin WP, Lin J, Horng LC, Chang SM, Jiang CC (2009) Quadriceps-sparing, minimal-incision total knee arthroplasty: a comparative study. J Arthroplasty 24(7): 1024-1032.

22. Matsumoto T, Muratsu H, Kubo S, Mizuno K, Kinoshita K, et al. (2011) Soft tissue balance measurement in minimal incision surgery compared to conventional total knee arthroplasty. Knee Surg Sport Tr A 19(6): 880-886.

23. Shen H, Zhang XL, Wang Q, Shao JJ, Jiang Y (2007) Minimally invasive total knee arthroplasty through a quadriceps sparing approach: a comparative study. Zhonghua Wai Ke Za Zhi 45(16): 1083-1086.

24. Lin SY, Chen CH, Fu YC, Huang PJ, Lu CC, et al. (2013) Comparison of the clinical and radiological outcomes of three minimally invasive techniques for total knee replacement at two years. Bone Joint J 95-B(7): 906-910.

25. Jie X, Chun-hua L, Shi-guo Z, Yuan L (2013) Total knee arthroplasty: Comparison between quadriceps sparing approach and medial parapatellar approach. Chinese journal of Tissue Engineering Research 17(35): 6240-6246.

26. Dalury DF, Dennis DA (2005) Mini-incision total knee arthroplasty can increase risk of component malalignment. Clin Orthop Relat Res 440: 77-81.
Creative Commons Attribution 4.0 International License

For possible submissions Click Here

\section{Submit Article}

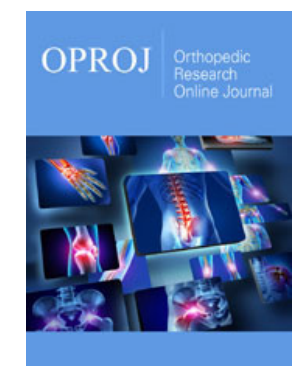

Orthopedic Research Online Journal

\section{Benefits of Publishing with us}

- High-level peer review and editorial services

- Freely accessible online immediately upon publication

- Authors retain the copyright to their work

- Licensing it under a Creative Commons license

- Visibility through different online platforms 